reciDioc
International Journal of Dentistry and Oral Science (IJDOS)

ISSN: $2377-8075$

\title{
Clinical and Radiographic Evaluation of Using White Portland Cement and MTA in Pulpotomy Pri- mary Anterior Teeth: A Randomized, Split-Mouth, Controlled Clinical Trial with 12 Months Follow-Up
}

Research Article

\author{
Hasan Alzoubi ${ }^{1}$, Nada Bshara ${ }^{2}$, Imad Katbeh ${ }^{3 *}$, Tamara Kosyreva ${ }^{4}$, Saleh Alkurdi ${ }^{5}$, Leen Droubi ${ }^{6}$
}

${ }^{1}$ MSc student, Faculty of Dentistry, Department of Pediatric Dentistry, Damascus University, Syria.

${ }^{2}$ Professor, Faculty of Dentistry, Department of Pediatric Dentistry, Damascus University, Syria.

${ }^{3}$ Assistant Professor, Department of Pediatric Dentistry and Orthodontics, Peoples' Friendship University of Russia (RUDN University), 117198 Miklukho-Maklaya Street 6, Moscow, Russia.

${ }^{4}$ Professor, The Head of the Department of Paediatric Dentistry and Orthodontics RUDN University (People's Friendship University of Russia). Russia, Moscow, 117198, Miklukho-Maklaya.

${ }^{5}$ PhD Student, Faculty of Dentistry, Department of Pediatric Dentistry, Damascus University, Syria.

${ }^{6}$ MSc Student, Faculty of Dentistry, Department of Pediatric Dentistry, Damascus University, Syria.

\section{Abstract}

The purpose of the present controlled trial was to evaluate the clinical and radiographical success rate of pulpotomies in carious vital primary anterior teeth using White Portland (WPC) cement versus White MTA.

Materials and Methods: Sixty asymptomatic carious vital primary anterior teeth with pulp exposure in healthy children aged 4 to 9 years were allocated randomly to receive WPC or WMTA pulpotomy. Clinical and radiographical post-treatment assessments occurred at 3,6,12 months. Primary anterior teeth treated with pulpotomy were classified into one of the following radiographic outcomes: $\mathrm{N}=$ primary anterior teeth without pathologic change; $\mathrm{Po}=$ pathologic change present, follow-up recommended; $\mathrm{Px}=$ pathologic change present, extract.

Results: All studied pulpotomy cases were clinically and radiologically successful regardless of the material used and whatever the time period between WPC and WMTA pulpotomy group in the three studied time periods (3,6,12 months) so that no statistical differences in clinical or radiographical outcomes between WPC and WMTA primary anterior teeth pulpotomy. Conclusion: WMTA or WPC pulpotomy were effective in the treatment of carious vital primary anterior teeth. PC may serve as a good alternative to MTA for pulpotomy of primary teeth.

Keywords: Pulpotomy; Primary Anterior Teeth; White Mta; White Portland Cement.

\section{Introduction}

Early childhood caries still poses a challenge to dental practitioners as it leads to significant loss of the dental arch length leading to problems with space maintenance, pronunciation difficulties, lack of masticatory forces and the development of nonfunctional habits. Therefore, modern pediatric dentistry seeks to preserve the functional, aesthetic and developmental capacity of primary teeth $[1,2]$.
Because of the small size of these teeth, endodontic exposures occur early. In this case, the traditional treatment is root canal treatment to preserve the development of the dental arch, the aesthetic and functional aspects, and the natural eruption of the permanent teeth [3].

Root canal treatment faces many difficulties, including the morphology of the root canals, the physiological resorption of the root of the primary teeth, and the failure to find an ideal filling material that resorbs at the same degree as the root.

\section{*Corresponding Author:}

Imad Katbeh,

Assistant Professor, Department of Pediatric Dentistry and Orthodontics RUDN University (Peoples' Friendship University of Russia), 117198 Miklukho-Maklaya Street 6, Moscow, Russia.

Tel: +79168268962

E-mail: katbeh@bk.ru

Received: July 21, 2021

Accepted: August 22, 2021

Published: September 03, 2021

Citation: Hasan Alzoubi, Nada Bshara, Imad Katbeh, Tamara Kosyreva, Saleh Alkurdi, Leen Droubi. Clinical and Radiographic Evaluation of Using White Portland Cement and MTA in Pulpotomy Primary Anterior Teeth: A Randomized, Split-Mouth, Controlled Clinical Trial with 12 Months Follow-Up. Int J Dentistry Oral Sci. 2021;8(9):4195-4200. doi: http://dx.doi.org/10.19070/2377-8075-21000855

Copyright: Imad Katbeh ${ }^{\circ} 2021$. This is an open-access article distributed under the terms of the Creative Commons Attribution License, which permits unrestricted use, distribution and reproduction in any medium, provided the original author and source are credited. 
Studies have shown high success rate of MTA, Portland cement, Biodentin and ferric sulfate pulpotomy in primary molars. This treatment is easy and fast and does not include interference along the canal or apical region $[6,7]$. Pulpotomy is defined as the removal of the entire coronal pulp tissue that is infected or expected to become inflamed as a result of pulp exposure or the arrival of infection to it, then covering the remaining root pulp tissue with a dressing material resulting in either healing of the pulp or fixation of the remaining pulp under the covering material in order to allow the tooth to perform its physiological function. [8, 9]. After the trend towards mineral trioxides (MTA) and the similarity in composition and properties observed between this material and Portland Cement, in addition to the high price of MTA compared to Portland cement $[10,11]$.

Therefore, this study was proposed to evaluate the use of MTA and Portland cement in primary anterior teeth pulpotomy in order to suggest it as a safe, simple, and economical alternative with high success rates in exposed pulps of primary anterior teeth.

\section{Materials and Methods}

\section{Trial design}

A randomized controlled trial by split mouth design was conducted in healthy 4- to 9-year-old children that had primary anterior teeth indicated forpulpotomy treatment and followed up clinically and radiographically for 3,6,12 months.

\section{Ethical considerations}

The study protocol was approved by scientific research and Postgraduate Board of Damascus University Ethics Committee of Damascus University, Damascus, Syria (protocol code 1786 and date of approval 4 March 2019). The study protocol was also enrolled, and the full trial protocol can be accessed at clinicaltrials. gov (NCT04634123). A detailed information sheet in simple nontechnical language was provided in advance, and parents/guardians were requested to sign an informed consent. The patients and parents were blinded by not being provided any information about the treatment group to which they were allocated.

\section{Study population and inclusion criteria}

Healthy children, 4 to 9year- old, with one or more split mouth carious asymptomatic primary anterior teeth where removal of dental caries was likely to produce vital pulp exposure were invited to participate in the investigation. Eligible teeth were included in the study if they fulfilled the following requirements: caries include a maximum of two surfaces to be restored; pulp exposure during caries removal; pulpal hemorrhage light red with achievable hemostasis; physiological root resorption no more than the apical third. Exclusion criteria included: children with systematic or mental disorders; history of spontaneous pain; presence of any clinical and radiographic signs which indicate pulpal necrosis; such as internal or external root resorption, inter-radicular and/ or periapical bone destruction, existence periapical translucency, swelling or sinus tract, tenderness to percussion, pathological movement.

\section{Sample size and power calculation}

Sample size was determined using a sample size calculation program (PS Power and Sample Size Calculation Program, Version 3.0.43). Sample size was calculated using outcomes from Nguyen T. D. et al.comparing MTA/FS pulpotomy and RCT outcomes [12]. Sample size calculation produced a required sample size of 52 primary anterior teeth per group to detect a significant difference ( $90 \%$ power, two-sided $5 \%$ significance level). The sample size was increased to $60(15 \%)$ to compensate for loss during follow-up or due to other causes of attrition.

\section{Randomization and Blinding}

The clinically and radiologically studied sample was randomly distributed using a lottery, where the numbers from 1 to 30 were written on paper cards representing the research cases according to the chronological sequence of their completion (No. 1 represents the first case to be treated ... and so on) and then they were randomly divided into two groups:

Group A (represents the group in which the right side was treated with White Portland Cement)

Group B (represents the group in which the left side was treated with the White MTA). The numbers shown in the table (1) carry the results of randomization of the clinical and radiographical study sample.

A double blinding was also adopted in this study so that both the patient and the examiner were not know about the applied substance.

\section{Treatment procedure}

All dental treatment were provided in Damascus University-Faculty of Dentistry-Department of Pediatric Dentistry with local anesthesia and rubber dam isolation Figure (1) (A,a). Following caries removal and pulp exposure Figure (1) (B,b), the pulp chamber was accessed using a sterile no. 56 bur with a water-cooled high-speed hand piece. The access wasbe refined using a sterile no. 4 or 6 round bur in a slow-speed hand piece. For pulpotomy, the coronal pulp was amputated to a depth of approximately two millimeters below the free gingival margin with a slow speedhandpiece Figure (1) (C,c). Then the pulp chamber was flushed with sterile water from an air water syringe for 10 to 15 seconds. If hemostasis was not achieved, the tooth would be eliminated from the study. If hemostasis was achieved, WMTA (ProRoot ${ }^{\circledR}$ MTA Root Repair Material, Dentsply, Maillefer) or WPC (Aal-

Table 1. Randomization results for clinical and radiological study sample.

\begin{tabular}{|c|c|}
\hline Group A & Group B \\
\hline (White Portland Cement) & (White MTA) \\
\hline $1-3-6-8-11-17-18-19-21-23-24-25-26-27-28$ & $2-4-5-7-9-10-12-13-14-15-16-20-22-29-30$ \\
\hline
\end{tabular}


borg, Sinai, Egypt) will be applied to the amputated pulp surface to a thickness of not less than one mm using an amalgam carrier Figure (1) (D,d). Excess WMTA or WPC was removed, and the pulp chamber then sealed with glass ionomer cement (Fuji IX ${ }^{\circledR}$, GC Corporation, Tokyo, Japan) Figure (1) (E,e). The tooth was restored with resin composite (Filtek Z250 ${ }^{\circledR}$, 3M ESPE, St. Paul, MN, USA) immediately Figure (1) (F,f). Teeth were assessed at 3-, 6- and 12-months post-treatment.

\section{Outcome assessment}

Clinical findings assessed include presence or absence of the treated teeth, presence of restoration and if present whether the restoration was intact or not, localized gingival erythema, swelling, fistula/sinus tract, pathological tooth mobility, tenderness to percussion and tenderness to palpation. Clinical findings that were considered unacceptable outcomes include spontaneous or stimulant pain, tenderness to percussion, fistula/sinus tract, soft tissue swelling and/or pathological tooth mobility associated with the pulp treated tooth. Radiographical outcomes were categorized using the rating scale published in Doyle et al [13] who classified each treated tooth into one of three outcomes based on radiographic evaluation: $\mathrm{N}=$ anterior primary teeth without pathologic change; $\mathrm{Po}=$ pathologic change present, follow-up recommended; and $\mathrm{Px}=$ pathologic change present, extract. Primary anterior teeth rated $\mathrm{N}$ or Po were considered an acceptable radiographical outcome while incisors rated as Px were considered unacceptable. Radiographical findings assessed included presence or absence of periapical radiolucency, pathological external root resorption, widened PDL space, physiological root resorption, internal root resorption, dentin bridge formation and whether the restoration was intact or not.

\section{Statistical methods}

Data were analyzed at various follow-up periods. Intergroup differences stratified by age, gender, and type of tooth were statistically analyzed using Fisher's exact test. The software used for statistical analysis was SPSS 20.0 software for Windows (IBM Corp., Armonk, NY, USA). All tests applied were two tailed, and a $\mathrm{p}$ value of 0.05 or less was considered as a statistically significant intergroup difference.

\section{Results}

A total of 60 teeth treated with pulpotomy were studied: 30 teeth $(50 \%)$ treated with White Portland cement and 30 (50\%) with WMTAFigure (2). The study included 23 healthy children (13 boys and 10 girls). Their ages ranged between 4 and 9 years at the time of treatment, with a mean age of $5.3 \pm 1.4$ years (median of 5 years) in both groups. Of the 60 teeth treated with pulpotomy, $13(56.5 \%)$ of the teeth were from boys and $10(43.5 \%)$ were from girls.

Primary canines were the most common teeth treated with pulpotomy $(50 \%)$ followed by primary central incisors $(30 \%)$, and then the least common were the primary lateral incisors $(20 \%)$.

All studied pulpotomy cases were clinically and radiologically successful $(100 \%)$ regardless of the material used. There was no statistical difference in clinical or radiographical outcomes for WPC or WMTA pulpotomy primary anterior teethin the three studied time periods (3,6,12 months) Figure (3).

\section{Dentine bridge formation}

The value of the chi-square test to study the significance of the differences in the formation of the dentine bridge radiographically between the two groups according to the material used (WPC /WMTA) in the time period after three months was (0.111), and the p-value was (0.739), which is greater than the significance level (0.05), and in the time period after six months and after twelve months were $(0.218)$ and the $\mathrm{p}$-value was $(0.640)$, which is greater than the significance level (0.05), therefore there are no statistically significant differences in the frequency of dentinal bridge formation radiographically between the two groups according to the material used and the time period studiedtable (2).

\section{Discussion}

Pulpotomy is an effective choice for vital pulp therapy in carious pulp exposure in primary anterior teeth [14], that limits intervention through vitality preservation, decreasing the need for pulpectomy and unnecessary extractions and improving children's quality of life [15]. The main aim of the present study was to compare the effectiveness of pulpotomy in human primary anterior teeth using White Portland cement with those performed with White MTA and its results show that both materials have high success rates of up to 12 months, like those found in PCstudy [16].

MTA was selected as the control group because it has been considered the "gold standard" for vital pulp therapy in primary teeth [17].

The high success rate of pulpotomy with PC (100\%) found in our study is impressive, but the results should be further tested with longer follow-up periods. Vilimek, Gateva et al found a success rate of $92.96 \%$ for PC pulpotomies in primary incisors and

Table 2. Shows the results of the chi-square test to study the significance of the differences in the formation of the dentine bridge.

\begin{tabular}{|c|c|c|c|c|}
\hline $\begin{array}{c}\text { The time period } \\
\text { studied }\end{array}$ & $\begin{array}{c}\text { Number } \\
\text { of cases }\end{array}$ & chi-square & p-value & $\begin{array}{c}\text { The significance of the } \\
\text { differences }\end{array}$ \\
\hline $\begin{array}{c}\text { After three } \\
\text { months }\end{array}$ & 60 & 0.111 & 0.739 & $\begin{array}{c}\text { no statistically significant } \\
\text { differences }\end{array}$ \\
\hline After six months & 60 & 0.218 & 0.64 & $\begin{array}{c}\text { no statistically significant } \\
\text { differences }\end{array}$ \\
\hline $\begin{array}{c}\text { After twelve } \\
\text { months }\end{array}$ & 60 & 0.218 & 0.64 & $\begin{array}{c}\text { no statistically significant } \\
\text { differences }\end{array}$ \\
\hline
\end{tabular}


Figure 1. (a) and (A) Isolation with rubber dam, (b) and (B) caries removal and pulp exposure, (c) and (C) accessing the pulp chamber with achieving hemostasis, (d) White Portland Cement application, (D) White MTA Application, (e) and (E) Application of glass ionomer cement as base filling, (f) and (F) rubber dam removal and final restoration with composite resin.
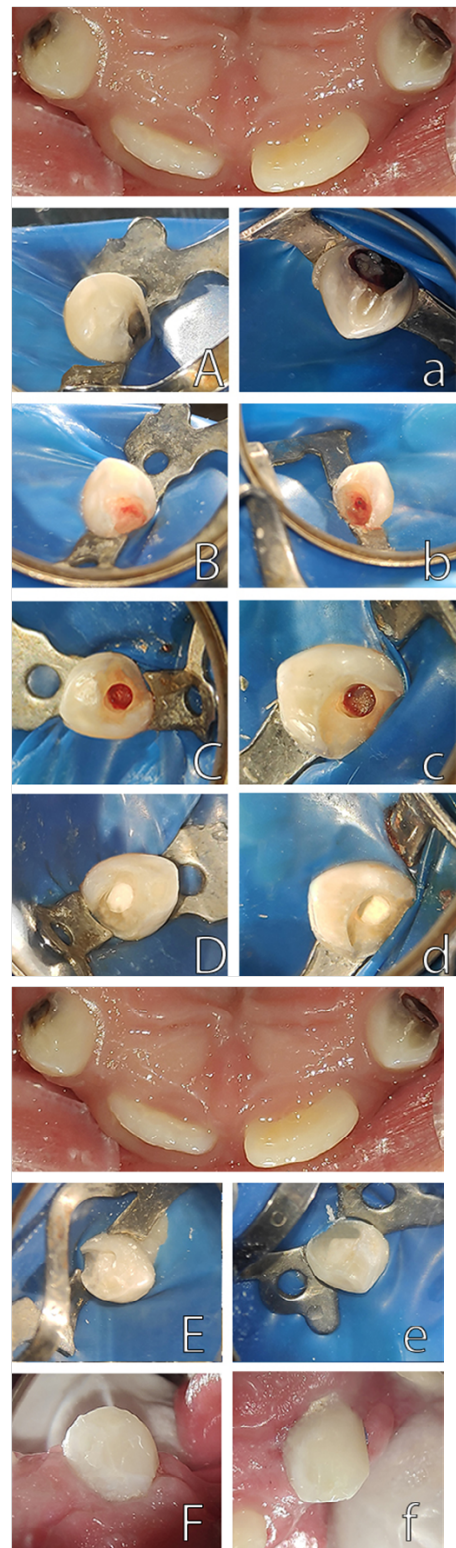

Figure 2. Allocation flow diagram.

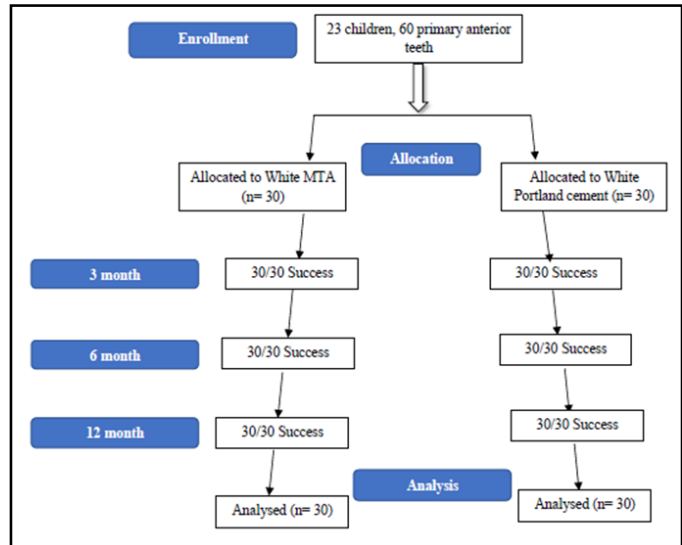

molars performed under general anesthesia [18].

The difference was the inclusion criteria where teeth with symptoms of inflamed pulps were included. An advantage of this study was the strict adherence to teeth where the condition of the pulp is appropriate for pulpotomy.
According to the literature, the two most common reasons for pulpotomy failures in primary teeth are misdiagnosis of radicular pulp inflammation preceding to treatment and pulp contamination due to micro-leakage $[19,20]$. In this study, these issues can explain the high success rates for WPC pulpotomy Where the 
Figure 3. Radiographical follow-up of a treatment case with WPC and WMTA.

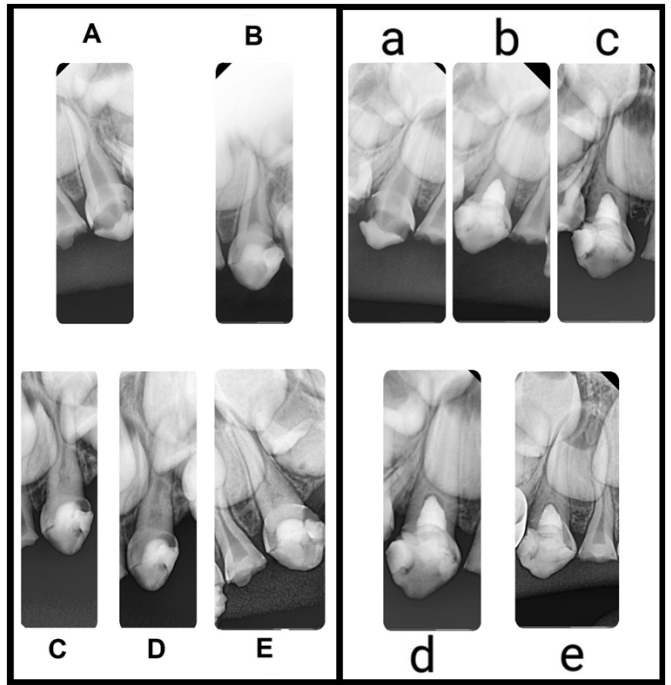

(A) diagnostic image (WPC),(a) diagnostic image (WMTA).

(B) immediately after treatment(WPC), (b) immediately after treatment (WMTA).

(C) first follow-up after 3 months (WPC),(c) first follow-up after 3 months (WMTA).

(D) Second follow-up after 6 months (WPC),(d) Second follow-up after 6 months (WMTA).

(E) Third follow-up after 12 months (WPC),(e) Third follow-up after 12 months (WMTA).

treatment was completed in one session and thus marginal leakage was minimal.

Hard tissue barrier was a radiographical finding in most of the cases in the PC group. This phenomenon has been described in both animal and humanstudies [21-23]. We suggest that the hard tissue barrier is a dentin bridge and propose the following suitable clarification for this phenomenon; pure Portland cement contains calcium oxide that structures calcium hydroxide when mixed with water. The calcium particles react with the carbon dioxide from the pulp tissue and calcite crystals are produced. A rich extracellular network of fibronectin forms closely to the calcite crystals. This is the initial step of a hard tissue barrier formation, also known as dentin bridge.

Esthetics is detailed worry of clinicians and guardians in pulp treated primary incisors [24]. MTA, ZOE, Endoflas and iodoform are obturation materials reported to have the potential to discolor coronal tooth structure in primary teeth. Tooth-colored ProRoot MTA has demonstrated gray discoloration in this study like those found in other studies $[25,26]$. The mechanism of MTA discoloration is still not fully understood, but recent evidence suggests tooth discoloration is associated with metallic black bismuth oxide shaped from the reaction of bismuth oxide with light in a non-oxygenated environment [27]. While White Portland cement was color-stable, and this is explained by the absence of bismuth oxide in its composition.

Another clinical advantage of pulpotomyon primary anterior teeth by WPC/WMTA is the fact that less time is needed for the procedure and the treatment can be done in one visit.

A limitation of this study was that the study period is short. Highly reliable results can be attained by future studies with large sample size and long -time follow-up.

\section{Conclusion}

White Portland cement and White MTA were successful in 100\% of the cases with no differences between the two treatments. Based on this study's results, it can be concluded that there is no superiority of one material over the other and White Portland cement can be used in primary anterior teeth pulpotomy.

Acknowledgments: The authors thank all of the study participants for their time and insight. Additional thanks go to Damascus University and Head of Pediatric dentistry Mohamad Kamel Altinawi.

\section{References}

[1]. Wanderley MT, Ferreira SL, Rodrigues CR, Rodrigues Filho LE. Primary anterior tooth restoration using posts with macroretentive elements. Quintessence Int. 1999 Jun;30(6):432-6.Pubmed PMID: 10635281.

[2]. Aminabadi NA, Farahani RM, Gajan EB. A clinical study of formocresolpulpotomy versus root canal therapy of vital primary incisors.J ClinPediatr Dent. 2008 Spring;32(3):211-4.Pubmed PMID: 18524271.

[3]. Primosch RE, Ahmadi A, Setzer B, Guelmann M. A retrospective assessment of zinc oxide-eugenol pulpectomies in vital maxillary primary incisors successfully restored with composite resin crowns. Pediatr Dent. 2005 NovDec;27(6):470-7.Pubmed PMID: 16532887.

[4]. Fuks A, Eidelman E, Pauker N. Root fillings with Endoflas in primary teeth: a retrospective study. J. Clin. Pediatr. Dent. 2003 Sep 1;27(1):41-5.

[5]. Barker BC, Parsons KC, Williams GL, Mills PR. Anatomy of root canals. IV deciduous teeth.Aust. Dent. J. 1975 Apr;20(2):101-6.

[6]. Yildiz E, Tosun G. Evaluation of formocresol, calcium hydroxide, ferric sulfate, and MTA primary molar pulpotomies. Eur J Dent. 2014 Apr;8(2):234240.Pubmed PMID: 24966776.

[7]. Carti O, Oznurhan F. Evaluation and comparison of mineral trioxide aggregate and biodentine in primary tooth pulpotomy: Clinical and radiographic study. Niger J ClinPract. 2017 Dec;20(12):1604-1609.Pubmed PMID: 29378994.

[8]. Shanthala BM, editor. McDonald and Avery's Dentistry for the Child and Adolescent--E Book: Second South Asia Edition. Elsevier Health Sciences; 2019 Mar 22.

[9]. ALAWWAD M, ALTINAWI M, REKAB MS, KOSYREVA T, ALMOKADDAM H, KATBEH I. A Randomised Clinical Radiological Study using Platelet Rich Fibrin and MTA in Pulpotomy of First Permanent 
Immature Molars. J ClinDiagn Res. 2020 Nov 1;14(11) :ZC1-ZC5.

[10]. Steffen R, Fadi AA, van Waes HJ. Pulpotomy-is MTA/Portland cement the future. Revolutions in paediatric Dentistry. London: Quintessenz. 2011:174-83.

[11]. Chakraborty A. Will Portland cement be a cheaper alternative to mineral trioxide aggregate in clinical use?: A comprehensive review of literature. Int J Contemp Dent Med Rev. 2015 Apr;2015:110215.

[12]. Nguyen TD, Judd PL, Barrett EJ, Sidhu N, Casas MJ. Comparison of Ferric Sulfate Combined Mineral Trioxide Aggregate Pulpotomy and Zinc Oxide Eugenol Pulpectomy of Primary Maxillary Incisors: An 18-month Randomized, Controlled Trial. Pediatr Dent. 2017 Jan 15;39(1):34-38.Pubmed PMID: 28292339.

[13]. Doyle TL, Casas MJ, Kenny DJ, Judd PL. Mineral trioxide aggregate produces superior outcomes in vital primary molar pulpotomy. Pediatr Dent. 2010 Jan-Feb;32(1):41-7.Pubmed PMID: 20298652.

[14]. Dhar V, Marghalani AA, Crystal YO, Kumar A, Ritwik P, Tulunoglu O, et al. Use of vital pulp therapies in primary teeth with deep caries lesions. Pediatr. Dent. 2017 Sep 15;39(5):146E-59E.

[15]. Ramos-Jorge J, Alencar BM, Pordeus IA, Soares ME, Marques LS, RamosJorge ML, et al. Impact of dental caries on quality of life among preschool children: emphasis on the type of tooth and stages of progression. Eur J Oral Sci. 2015 Apr;123(2):88-95.Pubmed PMID: 25557987.

[16]. Petel R, Ziskind K, Bernfeld N, Suliman H, Fuks AB, Moskovitz M. A randomised controlled clinical trial comparing pure Portland cement and formocresolpulpotomies followed from 2 to 4 years. Eur Arch Paediatr Dent.2020 Nov 11:1-6.

[17]. Bossù M, Iaculli F, Di Giorgio G, Salucci A, Polimeni A, Di Carlo S. Different pulp dressing materials for the pulpotomy of primary teeth: a systematic review of the literature. J. Clin. Med. $2020 \mathrm{Mar} ; 9(3): 838$

[18]. Vilimek VM, Gateva N, Christof BS. Success rate of MedCem Portland ce- ment as a pulp capping agent in pulpotomies of primary teeth.J. IMAB Annu. Proceeding Sci. Pap. 2018 Jan 3;24(1):1866-71.

[19]. Fuks AB. Vital pulp therapy with new materials for primary teeth: new directions and treatment perspectives. Pediatr. Dent. 2008 May 1;30(3):211-9.

[20]. Holan G, Fuks AB, Ketlz N. Success rate of formocresolpulpotomy in primary molars restored with stainless steel crown vs amalga. Pediatr Dent. 2002 May-Jun;24(3):212-6.Pubmed PMID: 12064493.

[21]. Junqueira MA, Cunha NNO, Caixeta FF, Marques NCT, Oliveira TM, Moretti ABDS, et al. Clinical, Radiographic and Histological Evaluation of Primary Teeth Pulpotomy Using MTA And Ferric Sulfate. Braz Dent J. 2018 Mar-Apr;29(2):159-165.Pubmed PMID: 29898062.

[22]. Barbosa, A.V.H. Human pulp pesponse to Portland cement and MTA. 2018. 33(1): 11

[23]. Marques N, Lourenço Neto N, Fernandes AP, Rodini C, Hungaro Duarte M, Rios D, et al. Pulp tissue response to Portland cement associated with different radio pacifying agents on pulpotomy of human primary molars. J Microsc. 2015 Dec;260(3):281-6.Pubmed PMID: 26258985.

[24]. Kupietzky A, Waggoner WF, Galea J. The clinical and radiographic success of bonded resin composite strip crowns for primary incisors. Pediatr Dent. 2003 Nov 1;25(6):577-81.

[25]. Boutsioukis C, Noula G, Lambrianidis T. Ex vivo study of the efficiency of two techniques for the removal of mineral trioxide aggregate used as a root canal filling material. J Endod. 2008 Oct;34(10):1239-42.Pubmed PMID: 18793929.

[26]. Maroto M, Barbería E, Planells PA, García-Godoy F. Dentin bridge formation after mineral trioxide aggregate (MTA) pulpotomies in primary teeth. Am. J. Dent. 2005 Jun 1;18(3):151.

[27]. Felman D, Parashos P. Coronal tooth discoloration and white mineral trioxide aggregate. J. Endod. 2013 Apr 1;39(4):484-7. 